\title{
Permanent Magnet Synchronous Machine Hybrid Torque Control
}

\author{
Florent Morel, Member, IEEE, Jean-Marie Rétif, Xuefang Lin-Shi, and Claire Valentin
}

\begin{abstract}
This paper presents a control scheme suitable for systems composed of a continuous process modulated in energy by a power converter with a finite number of topologies. To track the continuous reference values, a topology of the power converter is determined from a criterion based on a process state variable model and taking into account the possible topologies of the power converter. The proposed hybrid control scheme is applied to an electrical motor drive composed of an inverter coupled to a permanent magnet synchronous machine. An evolution which insures a fixed modulation frequency is also proposed. Experimental results validate the feasibility and effectiveness of the proposed schemes.
\end{abstract}

Index Terms-Direct control, hybrid dynamic systems, permanent magnet synchronous machine (PMSM), physical systems with switches (PSS).

\section{INTRODUCTION}

A LARGE number of industrial applications exist where the physical phenomena are very well described by differential equations. However, discrete variables are necessary to represent the behavior of a system with multiple topologies or modes. Modeling and control of physical systems with switches (PSS) has attracted considerable attention in recent years [1]. One class of PSS is composed of a continuous process controlled by an energy modulator that has a finite number of configurations. A hydraulic cylinder controlled by an on/off valve or a heating resistor connected to a contactor are some examples that belong to this class of PSS [2].

The original control strategy presented here can be applied to this class of PSS. The control scheme is based on a state variable model for both the energy modulator and the continuous process. For this model, there is a finite number of control vectors, depending on the possible configurations for the energy modulator. A formal approach has been developed to choose a configuration and its application time to track the continuous reference values. This strategy is the so-called one-step hybrid control (OSHC).

The PSS under consideration is composed of a permanent magnet synchronous machine (PMSM) and a two-level voltage inverter (Fig. 1). The PMSM constitutes the continuous process of this PSS and the inverter corresponds to the energy modulator. The continuous state-variables and the outputs of this PSS are the machine stator currents expressed in the rotor flux reference frame. The switching states of each inverter leg are

Manuscript received March 24, 2006; revised September 25, 2007.

F. Morel, J.-M. Rétif, and X. Lin-Shi are with the AMPERE, INSA de Lyon, 69621 Villeurbanne Cedex, France (e-mail: florent.morel@insa-lyon.fr).

C. Valentin is with the LAGEP, UCB Lyon1, CPE Lyon, 69622 Villeurbanne Cedex, France.

Digital Object Identifier 10.1109/TIE.2007.911938

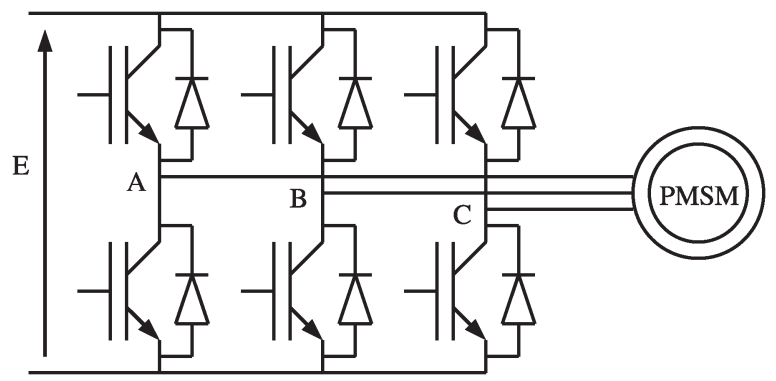

Fig. 1. Pilot physical system with switches.

the discrete state-variables of the PSS. Both continuous and discrete variables are considered for the hybrid control scheme application. The system considered is clearly hybrid (with continuous and discrete variables) so hybrid control strategies apply adequately.

For PMSM drives, vector control has been a standard for more than 20 years [3]. It does not take into account the discrete nature of the inverter states and does not realize a direct control of the switches. Indeed, the outputs of this controller are the mean voltages to be applied to the motor windings [4]. Because the inverter is considered by the controller as a gain, pulsewidth modulation (PWM) is used to translate these reference voltages into switching orders.

In the mid-1980s, the direct torque control (DTC) was developed to control torque and flux by directly choosing the configuration of the inverter [5]. It requires flux and torque estimators; torque and flux errors are used as inputs to hysteresis controllers and a look-up table is used to determine the appropriate configuration to minimize torque and flux errors [6] (Fig. 2). Compared to vector control, the advantages of DTC are lower dependence to machine parameters and a faster dynamic torque response [7]. However, to keep the electromagnetic torque and the flux inside hysteresis bands, a very short run-time is required for computation (generally $10 \mu \mathrm{s}$ ). Furthermore, hysteresis controllers induce a variable switching frequency which can lead to acoustic noise and is generally not suitable for electromagnetic interference issues.

Like DTC, OSHC applies to electric motor drives and directly determines the configurations of the inverter. However, there are significant differences: DTC is based on considerations on flux evolution tendency in the stator frame for a known voltage vector; OSHC is based on a formal representation of the set of the inverter and the machine and requires neither hysteresis controller nor observer. With DTC, a switching state is determined after a difference between references and estimations occurs. OSHC computes each future possible evolution 


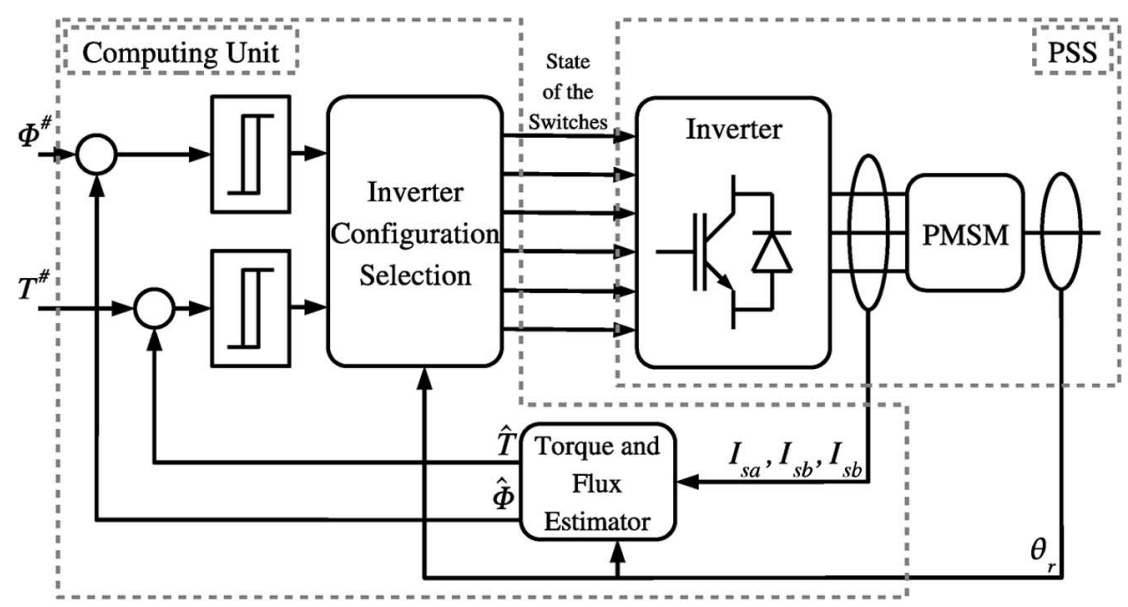

Fig. 2. Principle of DTC.

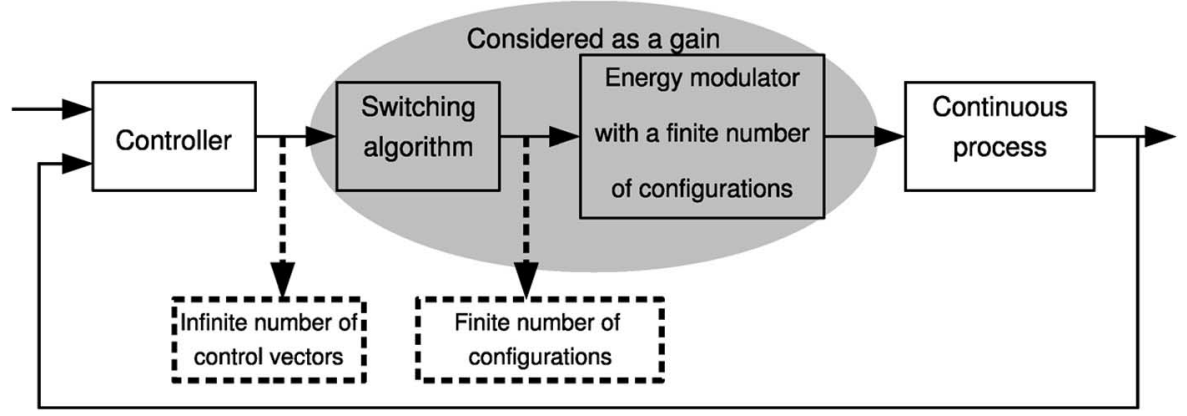

Fig. 3. Principle of classical control.

of the behavior of the system to determine switching states before a difference between references and measures occurs. OSHC requires a significant computing velocity as for DTC to reduce current ripples. An evolution of OSHC is presented in this paper. This strategy is the so-called multistep hybrid control (MSHC). The idea is to select more than one configuration of the converter during a computation period. The real-time constraints are less than for the OSHC.

The method presented in [8] uses Model Predictive Control (MPC) theory in combination with hybrid systems to determine the optimal set of switching states during a prediction horizon of 3. The comparative results with PI control show that the model predictive controller has better dynamic behavior than the PI control, but the static quality of the MPC is not so good. Moreover, the real-time constraint is large. In [9], thanks to a binary search tree, the real-time constraint of the MPC is reduced. However, the MPC has the same rise time as the PI controller because the inverter has not been integrated into the model.

In [10]-[12], the proposed predictive current control is quite similar to OSHC. However, [10] presents only simulation results and [11] presents experimental results for an $R-L$ load but not for an AC motor.

The main contribution of this paper compared to previous works is to propose a more formal and general control for PSS. It is general in the sense that it can be applied to different PSS. It has been applied to electrical drives, including PMSM, winding synchronous machine [13] and induction motor. It is also applied to electropneumatic systems for position control [14] and force control [15] of a pneumatic cylinder using on/off valves. In this context, in spite of the complexity and the strong nonlinearity of the state-space model, good performances are obtained with OSHC. For the case of electrical drives, the statespace model is a little bit simpler. However, the system dynamic is very fast with a time-constant a few hundred times less than the electropneumatic system. Another contribution of this paper is to improve OSHC with MSHC. Experimental results for a PMSM will show the effectiveness of MSHC.

This paper is organized as follows. The general principle of the OSHC is presented in Section II and its application to a PMSM is described in Section III. MSHC for a PMSM is presented in Section IV. Section V presents the experimental results with vector control, one-step and MSHC. Finally, a conclusion is given in the last section.

\section{HYBRID CONTROL}

In PSS "classical" control methods, the output of the controller is a control vector to be applied to the continuous process. A switching algorithm such as a PWM is used to translate this control vector into a sequence of configurations of the converter. The set of the energy modulator and the switching algorithm is considered as a gain (Fig. 3).

Hybrid control uses a hybrid model in which both the converter (or "energy modulator") and the continuous process are considered. In this model, there are continuous and discrete 


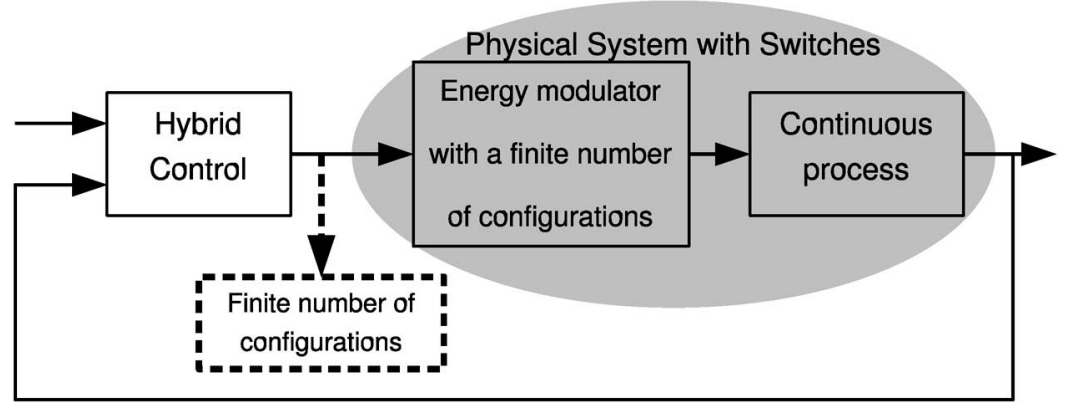

Fig. 4. Principle of hybrid control.

state-variables: the continuous state-variables are the statevariables of the continuous process; the discrete state-variables represent the configuration of the energy modulator (also called mode of the system). Hybrid control directly chooses the configurations of the converter (Fig. 4).

The hybrid model considered here corresponds to the controlled switching model defined in [1] and [16]

$$
\underline{\dot{X}}(t)=f(\underline{X}(t), \underline{U}(t))
$$

where $\underline{X}$ is the continuous state vector and $\underline{U}$ is the control vector depending on the configuration of the converter. At a given time, the control vector can only take a finite number of values. For a very short interval $\tau$, the model can be linearized as follows:

$$
\underline{X}(t+\tau)=\underline{X}(t)+f(\underline{X}(t), \underline{U}(t)) \cdot \tau .
$$

The model (2), linear or not, is used by the hybrid control and computed during each computation occurrence. Therefore, a very simple model validated only for a short time horizon is preferred.

During each computation occurrence, the state vector is measured, the model (2) is computed, so it is possible to determine, for each configuration $i$ of the converter, the direction of the continuous state vector evolution $\underline{d}_{i}$ corresponding to the application of the control vector $\underline{U}_{i}$ during $\tau$

$$
\underline{d}_{i}(t)=\underline{X}(t+\tau)-\underline{X}(t), \quad \text { with } \quad \underline{U}(t)=\underline{U}_{i}(t) .
$$

Once the $n$ possible directions of the continuous state vector evolutions $\underline{d}_{i}$ are calculated, the OSHC uses a strategy to choose a configuration of the converter to track the reference values $\underline{X}^{\#}$. The corresponding time of application $\tau^{\prime}$ is computed by assuming that during the application of a configuration of the converter, the evolution of the continuous state vector is a straight line and its amplitude is proportional to the time of application. This time is bounded by a maximum and a minimum value.

On the one hand, the assumption on the state vector evolution limits $\tau^{\prime}$ to a maximum time of application $\tau_{\max }$. On the other hand, due to technology limitations of the converter and/or CPU performance (computation cycle duration), $\tau^{\prime}$ must be larger than the duration of the algorithm calculation, so a minimum time of application $\tau_{\min }$ must also be respected.

The next section details the algorithm of OSHC for an inverter-fed PMSM.

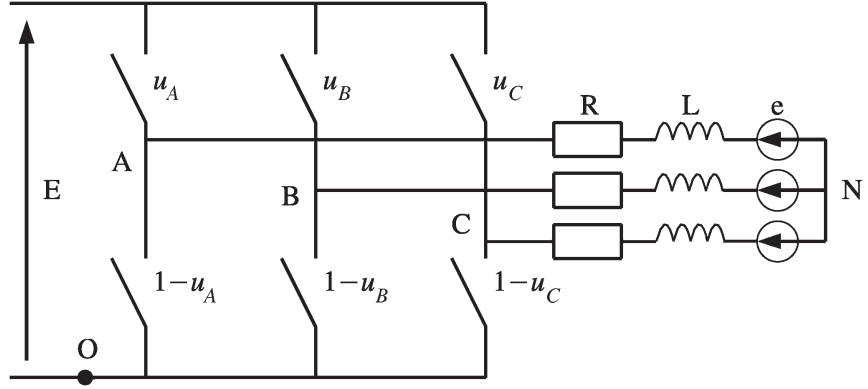

Fig. 5. Simplified representation of the inverter-fed PMSM.

\section{OSHC APPLIED TO A PMSM SUPPLIED BY AN INVERTER}

\section{A. Model for the Set of the Inverter and the PMSM}

The PMSM is modeled by continuous state-space equations written in the stator flux reference frame (4) [17]

$$
\begin{aligned}
{\left[\begin{array}{c}
\dot{I_{\mathrm{sd}}}(t) \\
\dot{I}_{\mathrm{sq}}(t)
\end{array}\right]=\left[\begin{array}{cc}
-\frac{R_{\mathrm{s}}}{L_{\mathrm{s}}} & \omega_{\mathrm{r}}(t) \\
-\omega_{\mathrm{r}}(t) & -\frac{R_{\mathrm{s}}}{L_{\mathrm{s}}}
\end{array}\right] \cdot\left[\begin{array}{c}
I_{\mathrm{sd}}(t) \\
I_{\mathrm{sq}}(t)
\end{array}\right] } \\
+\left[\begin{array}{cc}
\frac{1}{L_{\mathrm{s}}} & 0 \\
0 & \frac{1}{L_{\mathrm{s}}}
\end{array}\right] \cdot\left[\begin{array}{c}
V_{d}(t) \\
V_{q}(t)
\end{array}\right]+\left[\begin{array}{c}
0 \\
-\frac{\omega_{\mathrm{r}}(t)}{L_{\mathrm{s}}} \cdot \phi
\end{array}\right]
\end{aligned}
$$

where $I_{\mathrm{sd}}$ and $I_{\mathrm{sq}}$ are the $d$ - and $q$-axis stator currents, $R_{\mathrm{s}}$ is the stator phase resistance, $L_{\mathrm{s}}$ is the stator phase inductance, $\omega_{\mathrm{r}}$ is the rotor electrical speed, $V_{d}$ and $V_{q}$ are the $d$ - and $q$ axis voltages, and $\phi$ is the flux linkage established by the rotor. In the case of permanent magnets, $\phi$ is considered as a constant.

$V_{d}$ and $V_{q}$ voltages are imposed by the configuration of the inverter (switching states). The configurations of the inverter can be described by discrete variables $u_{\mathrm{A}}, u_{\mathrm{B}}$ and $u_{\mathrm{C}}$ in the following form (see Fig. 5):

$$
\begin{aligned}
& u_{\mathrm{A}}=\left\{\begin{array}{l}
0 \Leftrightarrow V_{\mathrm{AO}}=0 \\
1 \Leftrightarrow V_{\mathrm{AO}}=E
\end{array}\right. \\
& u_{\mathrm{B}}=\left\{\begin{array}{l}
0 \Leftrightarrow V_{\mathrm{BO}}=0 \\
1 \Leftrightarrow V_{\mathrm{BO}}=E
\end{array}\right. \\
& u_{\mathrm{C}}=\left\{\begin{array}{l}
0 \Leftrightarrow V_{\mathrm{CO}}=0 \\
1 \Leftrightarrow V_{\mathrm{CO}}=E .
\end{array}\right.
\end{aligned}
$$


TABLE I

CorRespondence Between the Configuration Number $(i)$ AND SWITCHING STATE OF EACH LEG

\begin{tabular}{c||c|c|c|c|c|c|c|c}
\hline$i$ & 0 & 1 & 2 & 3 & 4 & 5 & 6 & 7 \\
\hline \hline$u_{A}$ & 0 & 1 & 1 & 0 & 0 & 0 & 1 & 1 \\
\hline$u_{B}$ & 0 & 0 & 1 & 1 & 1 & 0 & 0 & 1 \\
\hline$u_{C}$ & 0 & 0 & 0 & 0 & 1 & 1 & 1 & 1 \\
\hline
\end{tabular}

The phase voltages can be written as in

$$
\left[\begin{array}{l}
V_{\mathrm{AN}}(t) \\
V_{\mathrm{BN}}(t) \\
V_{\mathrm{CN}}(t)
\end{array}\right]=\frac{E}{3} \cdot\left[\begin{array}{ccc}
2 & -1 & -1 \\
-1 & 2 & -1 \\
-1 & -1 & 2
\end{array}\right] \cdot\left[\begin{array}{l}
u_{\mathrm{A}}(t) \\
u_{\mathrm{B}}(t) \\
u_{\mathrm{C}}(t)
\end{array}\right]
$$

In the same way, these voltages can be expressed in the $\alpha \beta$ stator reference frame and multiplied by a rotation matrix to obtain the expressions of the voltages in the Park reference frame

$\underline{U}(t)=\left[\begin{array}{l}V_{d}(t) \\ V_{q}(t)\end{array}\right]=E \sqrt{\frac{2}{3}} R\left(\theta_{\mathrm{r}}\right) \cdot\left[\begin{array}{ccc}1 & -\frac{1}{2} & -\frac{1}{2} \\ 0 & \frac{\sqrt{3}}{2} & -\frac{\sqrt{3}}{2}\end{array}\right] \cdot\left[\begin{array}{l}u_{\mathrm{A}}(t) \\ u_{\mathrm{B}}(t) \\ u_{\mathrm{C}}(t)\end{array}\right]$

where $\theta_{\mathrm{r}}$ is the rotor position and

$$
R\left(\theta_{\mathrm{r}}\right)=\left[\begin{array}{cc}
\cos \theta_{\mathrm{r}} & \sin \theta_{\mathrm{r}} \\
-\sin \theta_{\mathrm{r}} & \cos \theta_{\mathrm{r}}
\end{array}\right]
$$

The correspondence between configuration number $(i)$ and the values of $u_{\mathrm{A}}, u_{\mathrm{B}}$ and $u_{\mathrm{C}}$ is given in Table I. Among the 8 possible configurations of the inverter, two of them (corresponding to $i=0$ and $i=7$ ) lead to $V_{d}=V_{q}=0$. As $\underline{U}_{0}=\underline{U}_{7}, i=0$ will not be considered from now on.

The stator voltages $V_{d}$ and $V_{q}$ corresponding to the $i$ th configuration can be calculated using (9). For a very short time $\tau,(4)$ and (9) can be written as (10) with the assumption that $\omega_{\mathrm{r}}$ and $\theta_{\mathrm{r}}$ are unchanged during $\tau$

$\underline{X}(t+\tau)=F\left(\omega_{\mathrm{r}}, \tau\right) \cdot \underline{X}(t)+H\left(\omega_{\mathrm{r}}, \tau, \theta_{\mathrm{r}}\right) \cdot \underline{U}(t)+\underline{\Phi}\left(\omega_{\mathrm{r}}, \tau\right)$

where $\underline{X}=\left[\begin{array}{ll}I_{\mathrm{sd}} & I_{\mathrm{sq}}\end{array}\right]^{t}$ is the continuous state vector and $\underline{U}=$ $\left[\begin{array}{lll}u_{\mathrm{A}} & u_{\mathrm{B}} & u_{\mathrm{C}}\end{array}\right]^{t}$ is the control vector.

Therefore, the continuous state vector after a time $\tau(\underline{X}(t+\tau))$ and the corresponding evolution in the state-space for the $i$ th control vector $\left(\underline{d}_{i}(t)\right)$ can be calculated with (10). Equation (10) forms the hybrid model (with continuous and discrete parts) of the set of the inverter and the PMSM.

\section{B. Control Algorithm}

The OSHC scheme applied to a PMSM consists of determining a configuration of the inverter and calculating its application time $\tau^{\prime}$ to track the desired references $I_{\mathrm{sd}}^{\#}$ and $I_{\mathrm{sq}}^{\#}$ (Fig. 6).

To track the reference values at each computation cycle the OSHC proceeds as follows.

1) The stator currents and rotor angular position are measured, the rotor speed is computed, $\underline{\Phi}\left(\omega_{\mathrm{r}}, \tau\right)$ and matrices $F\left(\omega_{\mathrm{r}}, \tau\right)$ and $H\left(\omega_{\mathrm{r}}, \tau, \theta_{\mathrm{r}}\right)$ are calculated.

2) For $1 \leq i \leq 7$, the direction $\underline{d}_{i}(k)$ of the continuous state vector evolution corresponding to the application of the

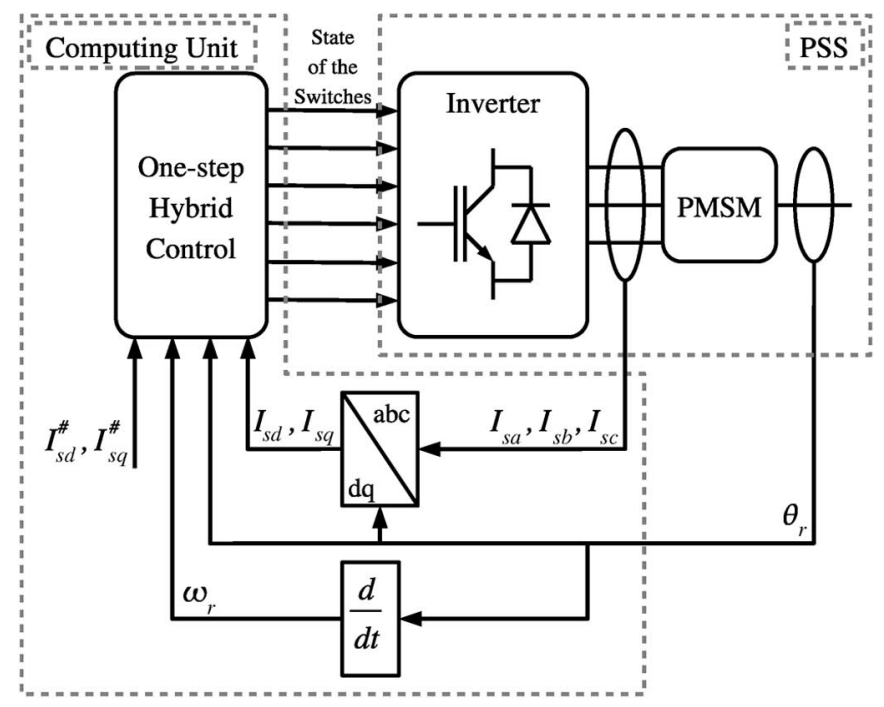

Fig. 6. Principle of the OSHC applied to inverter-fed PMSM.

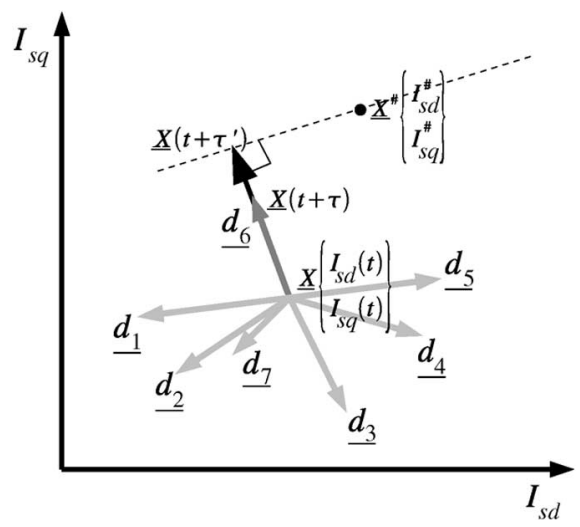

Fig. 7. State-space vector diagram at a given time.

$i$ th configuration of the inverter is calculated.

3) A configuration of the inverter is chosen using a cost function. There are many ways to define a cost function. For example, the angle between $\underline{d}_{i}(t)$ and $\left[\underline{X}^{\#}-\underline{X}(t)\right]$ can be a cost function.

4) The application time $\tau^{\prime}$ is calculated, for example with

$$
\begin{gathered}
\left|\underline{X}\left(t+\tau_{\text {opt }}\right)-\underline{X}^{\#}\right|=\min _{\Delta t}\left|\underline{X}(t+\Delta t)-\underline{X}^{\#}\right| \\
\left\{\begin{array}{lc}
\text { if } \quad \tau_{\text {opt }}<\tau_{\min } & \text { then } \tau^{\prime}=\tau_{\min } \\
\text { if } \tau_{\text {opt }}>\tau_{\max } & \text { then } \tau^{\prime}=\tau_{\max } \\
\text { else } & \tau^{\prime}=\tau_{\text {opt }} .
\end{array}\right.
\end{gathered}
$$

Fig. 7 shows an example of the seven possible directions in the state-space. The direction $\underline{d}_{7}$ corresponding to $V_{d}=V_{q}=0$ is not zero because it is the free response of the process. For this example, the configuration which minimizes the angle between $\underline{d}_{i}(t)$ and $\left[\underline{X}^{\#}-\underline{X}(t)\right]$ corresponds to $i=6$. At step 4 , the application time $\tau^{\prime}$ is computed to reach $\underline{X}\left(t+\tau^{\prime}\right)$.

Another possible cost function is the distance between $\underline{X}(t+$ $\left.\tau_{\min }\right)$ and $\underline{X}^{\#}$. In this case, step 4 is skipped $\left(\tau^{\prime}=\tau_{\min }\right)$ and the switching frequency is constant. This strategy can lead to a larger rise time during transient evolution, so it is used during steady-state operation. 


\section{Determination of a Reference State Vector}

The control of rotor position or speed of an electrical drive imposes the accurate control of its torque. For a PMSM, the electromagnetic torque is proportional to the current $I_{\mathrm{sq}}[3]$, then the minimization of the Joule power losses leads to maintain the current $I_{\text {sd }}$ equal to zero. Consequently, in the statespace, the reference values are $I_{\mathrm{sd}}^{\#}=0$ and $I_{\mathrm{sq}}^{\#}$ proportional to the desired torque.

The generation of a reference point is independent of the control proposed here (typically it is given by a "speed loop"). For control methods using space vectors, the future reference current $\underline{I}^{\#}(t+\tau)$ (in the stator reference frame) has to be predicted (for example using the Lagrange extrapolation formula [10]). Like in the steady-state operation, the components of the reference state vector $\left(I_{\mathrm{sd}}^{\#}\right.$ and $\left.I_{\mathrm{sq}}^{\#}\right)$ are constant, the reference state vector determination is simpler for hybrid control: $\underline{X}^{\#}(t+\tau)$ is considered equal to $\underline{X}^{\#}(t)$.

\section{Limitations}

Because there are only seven possible directions for the state vector, the reference point cannot be exactly reached with OSHC. In the case where the state vector is very near to the reference point, the application time is limited to $\tau_{\min }$, each switching state induces a state vector farther from the reference point. The smaller the $\tau_{\min }$ value, the nearer the state vector to the reference point. For a practical implementation, a high performance computing unit is required to reduce the duration of the algorithm calculation (a few microseconds for our application).

The advanced approach detailed in Section IV reduces this constraint by determining more than one configuration of the converter during a computation period. Furthermore, this algorithm gives a constant modulation frequency.

\section{MSHC FOR A PMSM SUPPLIED BY AN INVERTER}

With the OSHC scheme, the reference point cannot be exactly reached. Indeed, if only one configuration $i$ is selected, the possible evolution of the state vector is limited to a segment: the direction is $\underline{d}_{i}$, and the norm is proportional to the application time, which is between $\tau_{\min }$ and $\tau_{\max }$.

If two configurations ( $i$ and $j$ ) are selected and applied during $\tau_{i}$ and $\tau_{j}$, respectively, the set of the possible reached points represents a surface

$$
\frac{1}{\tau}\left(\tau_{i} \cdot \underline{d}_{i}+\tau_{j} \cdot \underline{d}_{j}\right), \quad \text { with } \quad \tau_{i, j} \in\left[\tau_{\min }, \tau_{\max }\right]
$$

Depending on the objective, there are two ways to compute the application times $\tau_{i}$ and $\tau_{j}$.

1) To exactly reach the reference point, $\tau_{i}$ and $\tau_{j}$ are computed in such a way that

$$
\frac{1}{\tau}\left(\tau_{i} \cdot \underline{d}_{i}+\tau_{j} \cdot \underline{d}_{j}\right)=\underline{X}^{\#}-\underline{X}
$$

In this case, the modulation period $\left(\tau_{i}+\tau_{j}\right)$ cannot be fixed $a$ priori.

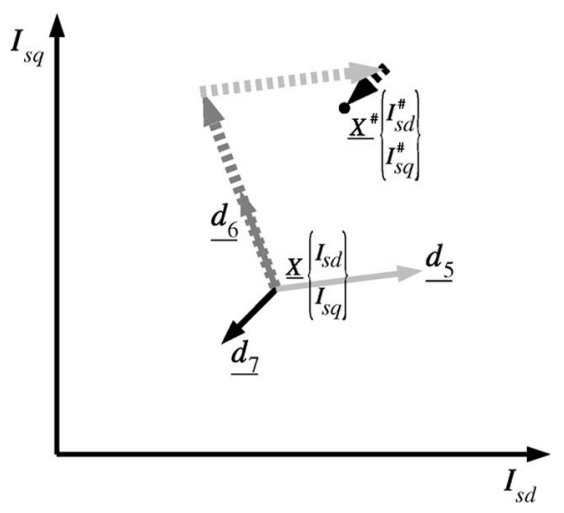

Fig. 8. Using two nonzero voltage configurations and a zero voltage configuration to reach the reference point after a modulation period.

2) If a fixed modulation period is desired, $\tau_{i}$ and $\tau_{j}$ are computed in such a way that $\tau_{i}+\tau_{j}=T$ where $T$ is the modulation period. This additional constraint means the set of accessible points to a segment is reduced. In this case, the reference point may not be exactly reached.

In summary, the linear combination of two vectors in the rotor flux reference frame does not allow reaching the reference point and obtaining a fixed modulation period. There are a few papers reporting control schemes applying two converter configurations by computing occurrence [18]-[21]. For example, [22] and [23] present different control schemes with the particularity of using two switching states during a fixed period. Reference [22] presents a scheme for the current control of a passive load: the application times of the two switching states are computed to minimize the norm of the current error vector. This vector cannot be exactly zero. The control scheme presented in [23] for a PMSM consists of applying a nonzero voltage vector and a zero voltage vector during a constant switching interval. Application times are computed to keep the torque in a ripple band. This control scheme allows good control of the mean torque and of its ripples, but it cannot control the flux evolution.

The scheme presented below allows both reaching of the reference point and obtaining a fixed modulation period.

\section{A. Principle of the Advanced Scheme}

The principle consists of applying two configurations corresponding to nonzero voltage $(1 \leq i \leq 6)$ and the configuration corresponding to zero voltages $(i=7)$ during a modulation period. The corresponding application times $\left(\tau_{i}, \tau_{j}\right.$ and $\left.\tau_{7}\right)$ are computed to exactly reach the reference point and to obtain a fixed modulation period T. See (Fig. 8) for a graphical representation.

This can be performed by solving three equations

$$
\left\{\begin{array}{l}
\tau_{i} \cdot d_{i d}+\tau_{j} \cdot d_{j d}+\tau_{7} \cdot d_{7 d}=T \cdot\left(X_{d}^{\#}-X_{d}\right) \\
\tau_{i} \cdot d_{i q}+\tau_{j} \cdot d_{j q}+\tau_{7} \cdot d_{7 q}=T \cdot\left(X_{q}^{\#}-X_{q}\right) \\
\tau_{i}+\tau_{j}+\tau_{7}=T .
\end{array}\right.
$$

1) The first equation corresponds to the constraint to reach the $d$-axis value of the reference point.

2) The second equation corresponds to the constraint to reach the $q$-axis value of the reference point. 


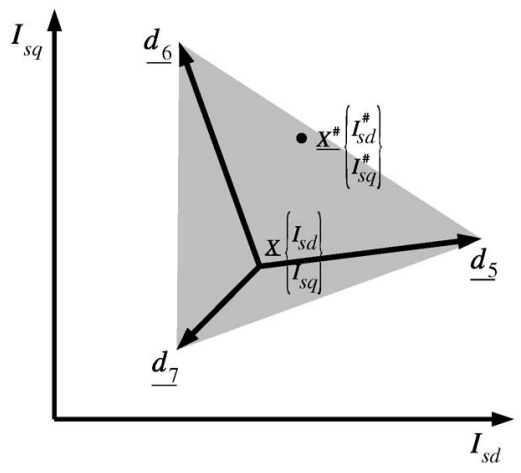

Fig. 9. Theoretically reachable points with configurations 5-7 ( $d_{x}$ length computed with $\tau=T$ ).

3) The last one corresponds to the constraint to have a constant modulation period.

In the case of Fig. 7, if configurations 5 and 6 are selected, solving (14) allows determination of $\tau_{5}, \tau_{6}$ and $\tau_{7}$ to reach the reference point $\underline{X}^{\#}$ (Fig. 8).

\section{B. Method for the Choice of Configurations}

To determine the configurations that allow reaching the reference point, it is necessary to know what the set of reachable points is when two vectors $i$ and $j(i, j \neq 7)$ are selected (reachability study). The surface corresponding to the set of points $1 / T\left(\tau_{i} \cdot \underline{d}_{i}+\tau_{j} \cdot \underline{d}_{j}+\tau_{7} \cdot \underline{d}_{7}\right)$ is limited by two constraints. The first one is obvious: values $\tau_{i}, \tau_{j}$ and $\tau_{7}$ must be positive. Second, the sum of the three application times must be equal to $T$. With these two constraints, when configurations $i$ and $j$ are selected, the set of points theoretically reachable is limited by a triangle joining the ends of $\underline{d}_{i}, \underline{d}_{j}$ and $\underline{d}_{7}$ (region in gray in Fig. 9). When the reference point is included in this triangular shaped surface, it can be exactly reached by the successive application of configurations $i, j$ and 7 .

To minimize the number of commutations in the inverter legs, two consecutive active configurations (configurations that differ by only one inverter leg state) are selected. Fig. 10 presents all the triangular-shaped regions formed by all pairs of two consecutive active configurations by taking into account a practical minimum application time constraint. It is interesting to note that, unlike the scheme presented in Section III, the value of $\tau_{\min }$ is not limited by the algorithm run-time but by the dead-time of the inverter. It can be seen that there are points in the state-space that cannot be reached after a modulation period (points not covered by a gray triangle). For these points, whatever the chosen configurations, solution of (14) leads to inapplicable results (application times less than $\tau_{\min }$ or even negative). In these cases, a set of rules similar to (12) can be applied to ensure that the reached point is on the limit of a reachable region.

A simple heuristic approach to choose active configurations consists of selecting the configurations corresponding to directions $\underline{d}_{i}$ and $\underline{d}_{j}$, which are the nearest ones on both sides of the objective point. When $\left|\underline{X}^{\#}-\underline{X}\right|$ is great compared to the norm of $\underline{d}_{7}\left(\underline{d}_{j}\right.$ vector norms are calculated with $\left.\tau=T\right)$, this strategy gives the right choice. However, it has been shown in simulation that this strategy induces bad choices when $\left|\underline{X}^{\#}-\underline{X}\right|$ is very

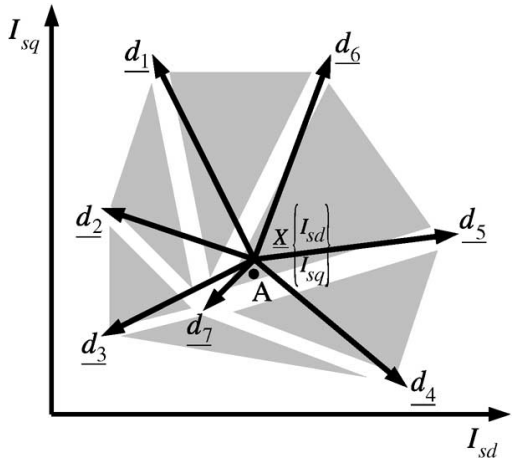

Fig. 10. Reachable regions considering a minimal application time.

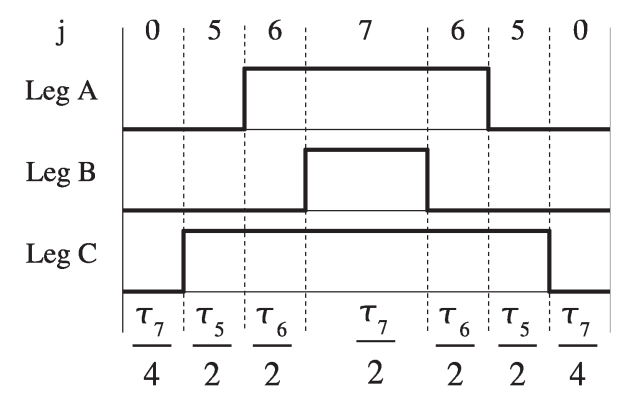

Fig. 11. Sequence of configurations during a modulation period.

small compared to the norms of vectors $\underline{d}_{j}$. For example, in the case of Fig. 10, if $A$ is the reference point, configurations 3 and 4 are selected with this strategy. It can be seen that the reachable region corresponding to configurations 3 and 4 does not include the reference point A. However, the reference point can be exactly reached by choosing configurations 5 and 6 . This analysis leads to the following heuristic approach that was implemented for experiment.

When $\left|\underline{X}^{\#}-\underline{X}\right|$ is smaller than $\left|\underline{d}_{7}\right|$, the algorithm selects the two configurations corresponding to the nearest directions on both sides of $-\underline{d}_{7}$. In other cases, configurations corresponding to the nearest directions on both sides of the reference point are selected. It can be expressed as follows.

If $\left|\underline{X}-\underline{X}^{\#}\right|>\left|d_{7}\right|$, the chosen configurations are $i$ and $j$ such as

$$
\exists(a, b) \in \mathbf{R}^{+2} / \underline{X}^{\#}=a \cdot \underline{d}_{i}+b \cdot \underline{d}_{j}
$$

where configurations $i$ and $j$ differ in only one leg state.

Otherwise, chosen configurations are $i$ and $j$ such as

$$
\exists(a, b) \in \mathbf{R}^{+2} /-\underline{d}_{7}=a \cdot \underline{d}_{i}+b \cdot \underline{d}_{j}
$$

where configurations $i$ and $j$ differ in only one leg state.

This strategy validated by simulation leads to a significant improvement in current ripples during steady-state operation and it is simple enough to be performed in a real-time implementation.

\section{Sequence of Configurations During a Modulation Period}

To center the inverter voltage pulses during a modulation period, as for a classical space vector modulation (SVM), the chosen state vectors are applied successively during fractions of $\tau_{i, j, 7}$. As an example, if configurations 5 and 6 are selected, 


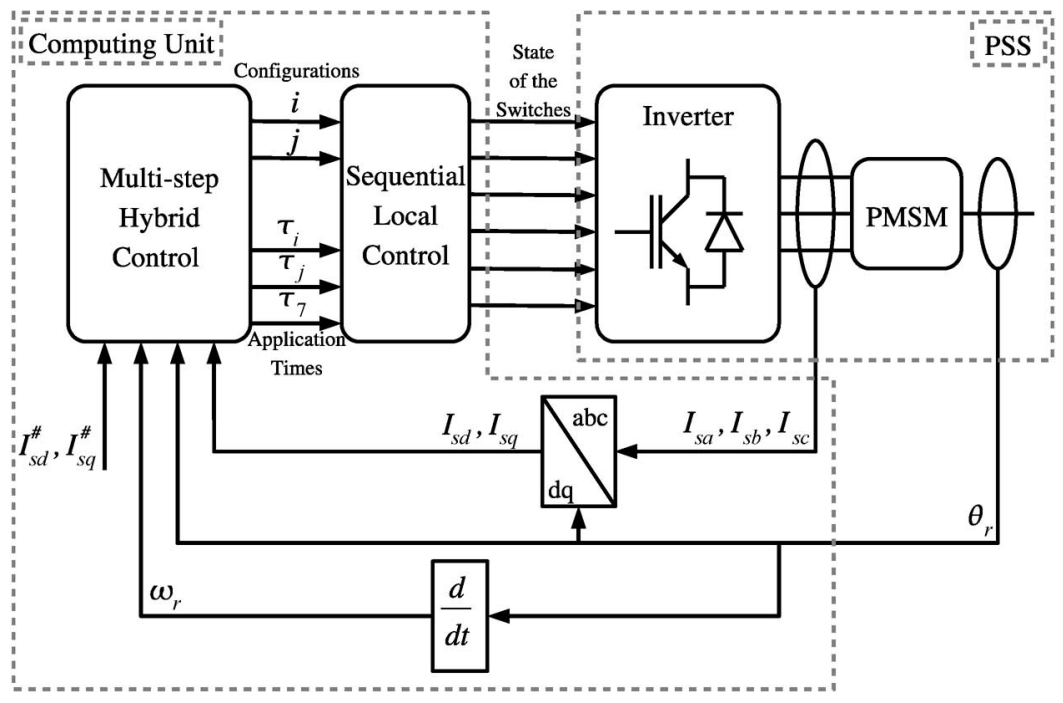

Fig. 12. Principle of the MSHC.

the configuration 0 is applied during $\tau_{7} / 4$, then configuration 5 during $\tau_{5} / 2$ and so on (Fig. 11). The main difference compared to control schemes using a classical SVM [24], [25] is that the SVM modulation creates a reference voltage vector in the $\alpha \beta$ reference frame with voltage vectors, and the modulation used here creates a succession of desired configurations (represented by the block Sequential Local Control in Fig. 12).

With this sequence of configurations, during each modulation period, the choice of configurations and the application time computation induce a succession of seven configurations. The corresponding state vector evolution is represented in Fig. 13. Thanks to this technique, oscillations of currents $I_{\mathrm{sd}}$ and $I_{\mathrm{sq}}$ are reduced during steady-state operation.

\section{EXPERIMENTAL RESULTS}

\section{A. Experimental Equipment}

The experiment was conducted with the equipment presented in Fig. 14. It is composed of a 1.5-kW PMSM with a 4096 pulse incremental encoder and three LEM current sensors. Another identical PMSM is used as a load torque generator. Parameters of the PMSM are given in Table II. The three phase inverter is supplied by a voltage source providing $300 \mathrm{~V}$ with a current limitation of about 6 A. Experimental results presented from Figs. $15-22$ correspond to a transient from $I_{\mathrm{sq}}^{\#}=-4$ A to $I_{\mathrm{sq}}^{\#}=$ $+4 \mathrm{~A}$ for different control strategies. The rotation speed of the motor changes from almost $-1250 \mathrm{r} / \mathrm{min}$ to almost $1250 \mathrm{r} / \mathrm{min}$. All experiments have been performed with the same inverter, the same PMSM and the same load.

\section{B. Vector Control}

A classical vector control technique using two PI regulators for $I_{\mathrm{sd}}$ and $I_{\mathrm{sq}}$ was implemented for comparative study. The output of these regulators are the winding voltages $V_{\mathrm{sd}}$ and $V_{\mathrm{sq}}$. SVM is used to convert these voltages into switching states.

The control algorithm is implemented in the Simulink environment. Computations are performed by a DSpace DS1102 controller board including a TMS320C31 DSP. The computa-

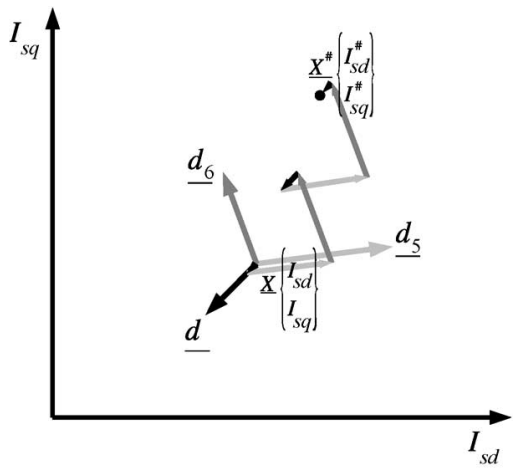

Fig. 13. State vector evolution with a sequence of configurations corresponding to Fig. 11.

tion period has been fixed to $1 \mathrm{~ms}$ and the PWM period has been set to $100 \mu \mathrm{s}$. For control schemes using a PWM modulation, six commutations (two for each inverter leg) correspond to a modulation period. Therefore, a $100 \mu$ s modulation period leads to an average commutation period of $50 \mu \mathrm{s}$ in an inverter leg. The discrete-time PI controllers have been calculated by pole assignment and correspond to $K_{p}=1.45$ and $T_{i}=4 \mathrm{~ms}$.

Fig. 15 shows the current waveforms where the reference value $I_{\mathrm{sq}}^{\#}$ is reached after $180 \mathrm{~ms}$. During transient operation, the current error for the $q$-axis reaches $1 \mathrm{~A}$ (25\% of the final value). The important difference (up to $3.3 \mathrm{~A}$ ) between $I_{\mathrm{sd}}^{\#}$ and $I_{\mathrm{sd}}$ during transient operation is due to the cross-coupling effect between $I_{\mathrm{sd}}$ and $I_{\mathrm{sq}}$. There is no static error thanks to the integral compensation used in the current loops. The current oscillations on $d$-axis reach 0.6 and $0.3 \mathrm{~A}$ for $q$-axis during steady-state operation.

Phase currents are presented in Fig. 16. An overshoot of 30\% is obvious in the absolute magnitude of currents. Currents reach $-4.5 \mathrm{~A}$, although during steady-state operation, the maximal value of currents is near 3.4 A.

\section{One-Step Hybrid Control (OSHC)}

OSHC was implemented on an Excalibur board, embedding a CPU-core (Nios-2 by Altera) inside an APEX20KE200 FPGA 


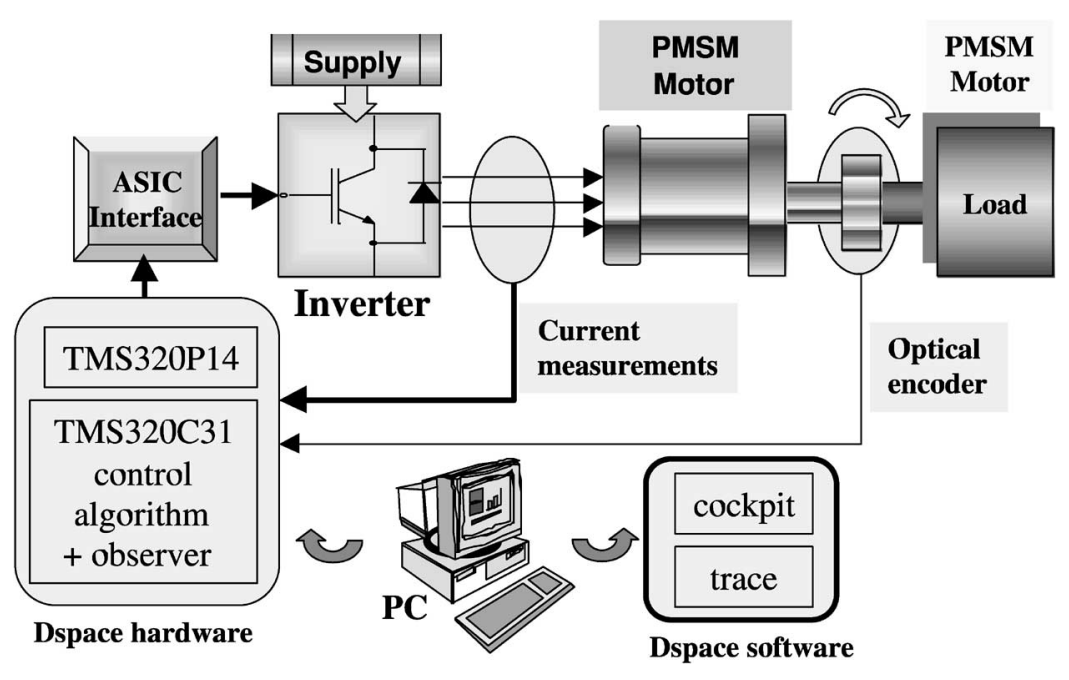

Fig. 14. Test Bench.

TABLE II

PARAMETERS OF THE PMSM

\begin{tabular}{l|l}
\hline Rated Torque & $5.5 \mathrm{Nm}$ \\
\hline Rated Speed & $3000 \mathrm{rpm}$ \\
\hline$R_{s}$ & $2.06 \Omega$ \\
\hline$L_{s}$ & $9.15 \mathrm{mH}$ \\
\hline$\phi$ & $0.29 \mathrm{~Wb}$ \\
\hline Number of pole pairs & 3 \\
\hline
\end{tabular}

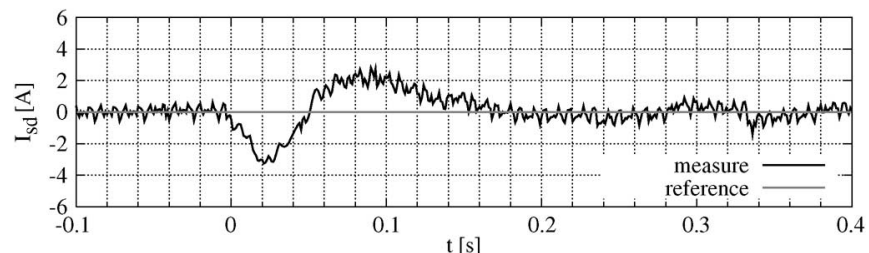

(a)

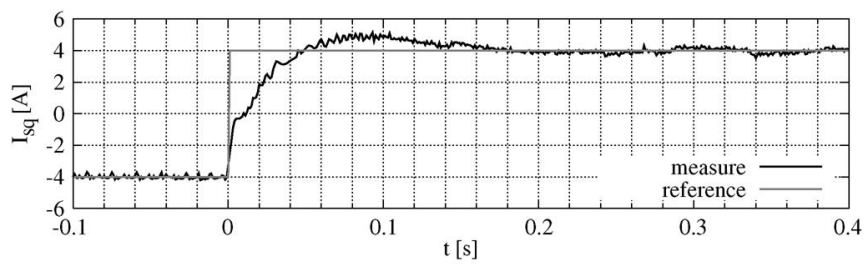

(b)

Fig. 15. Vector control: Evolution of the currents in the Park reference frame during a transient from $I_{\mathrm{Sq}}^{\#}=-4 \mathrm{~A}$ to $I_{\mathrm{Sq}}^{\#}=+4 \mathrm{~A}$. (a) $d$-axis. (b) $q$-axis.

by using a codesign approach. The duration of computation obtained is slightly less than $10 \mu \mathrm{s}$. Therefore the minimum application time $\tau_{\min }$ is fixed at $10 \mu \mathrm{s}$. The value of $\tau_{\max }$ is fixed at $100 \mu$ s after simulation studies. With the control scheme experimented here, the state of each leg switch can be changed after every computation cycle (10 $\mu$ s in the worst case, i.e., steady-state operation). As a result, the maximum commutation frequency is significantly increased compared to the previous experiment.

Figs. 17-19 show the $d$ - and $q$-axis current waveforms and phase current waveforms for OSHC. To reduce memory usage, data are recorded every $200 \mu \mathrm{s}$. The result shows that the

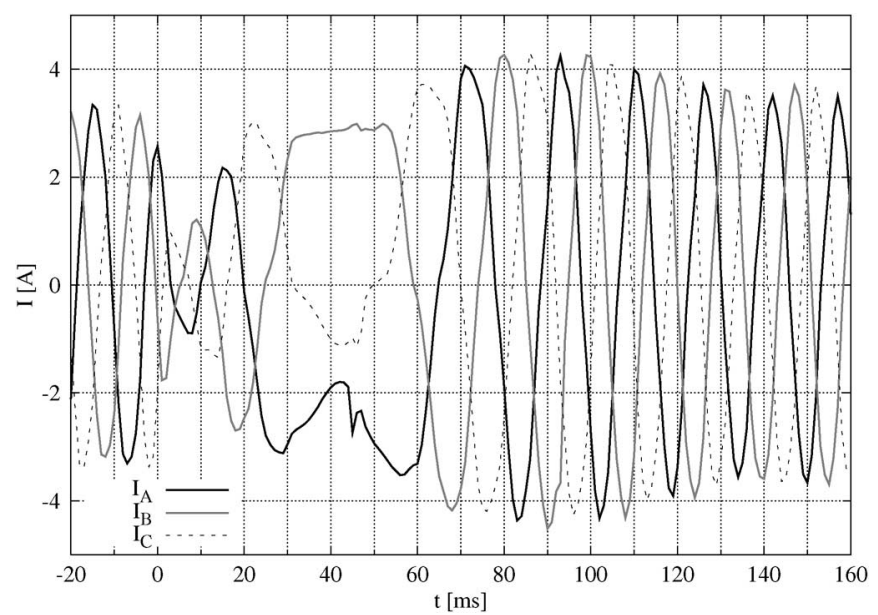

Fig. 16. Vector control: Evolution of the stator currents during a transient from $I_{\mathrm{sq}}^{\#}=-4$ A to $I_{\mathrm{sq}}^{\#}=+4 \mathrm{~A}$.

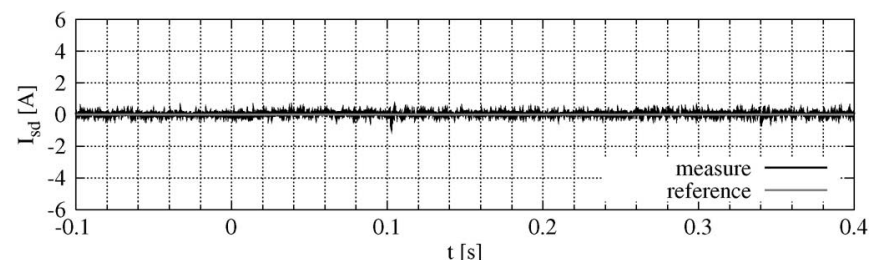

(a)

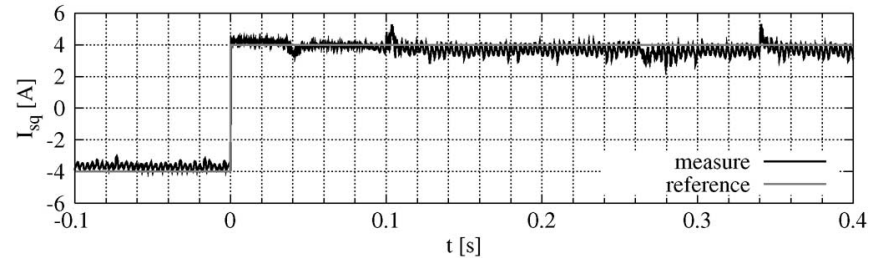

(b)

Fig. 17. OSHC: Evolution of the currents in the park reference frame during a transient from $I_{\mathrm{sq}}^{\#}=-4$ A to $I_{\mathrm{sq}}^{\#}=+4$ A. (a) $d$-axis. (b) $q$-axis.

steady-state operation is obtained without any overshoot either for $d$ - and $q$-axis currents, or for the phase currents. The duration of the current inversion (less than $500 \mu \mathrm{s}$ ) is greatly 


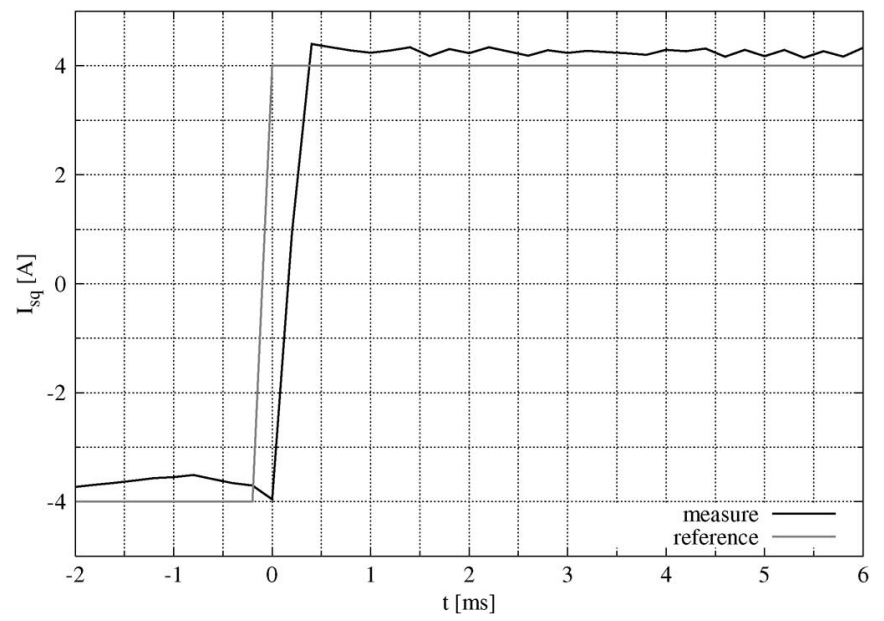

Fig. 18. OSHC: $q$-axis current evolution during a transient from $I_{\mathrm{Sq}}^{\#}=-4 \mathrm{~A}$ to $I_{\mathrm{sq}}^{\#}=+4 \mathrm{~A}$.

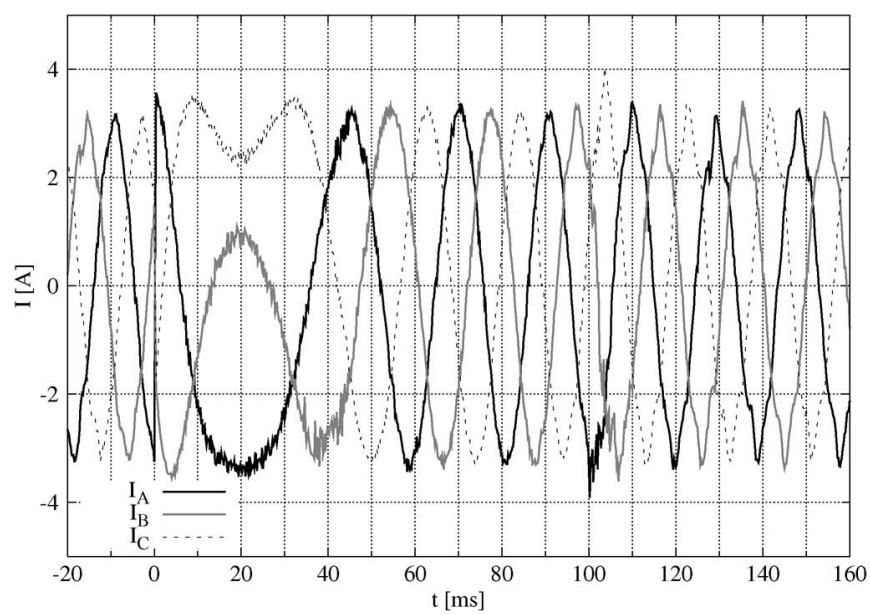

Fig. 19. OSHC: Evolution of the stator currents during a transient from $I_{\mathrm{sq}}^{\#}=$ -4 A to $I_{\mathrm{sq}}^{\#}=+4 \mathrm{~A}$.

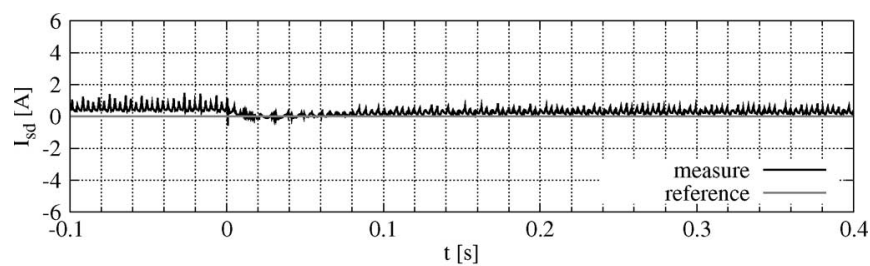

(a)

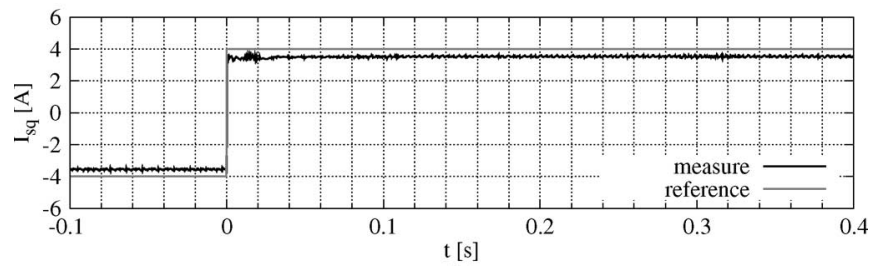

(b)

Fig. 20. MSHC: Evolution of the currents in the Park reference frame during a transient from $I_{\mathrm{sq}}^{\#}=-4$ A to $I_{\mathrm{sq}}^{\#}=+4 \mathrm{~A}$. (a) $d$-axis. (b) $q$-axis.

improved compared to vector control (Fig. 18). Nevertheless, in spite of the increased switching frequency in the inverter, $d$ and $q$-axis current oscillations during steady-state operation are

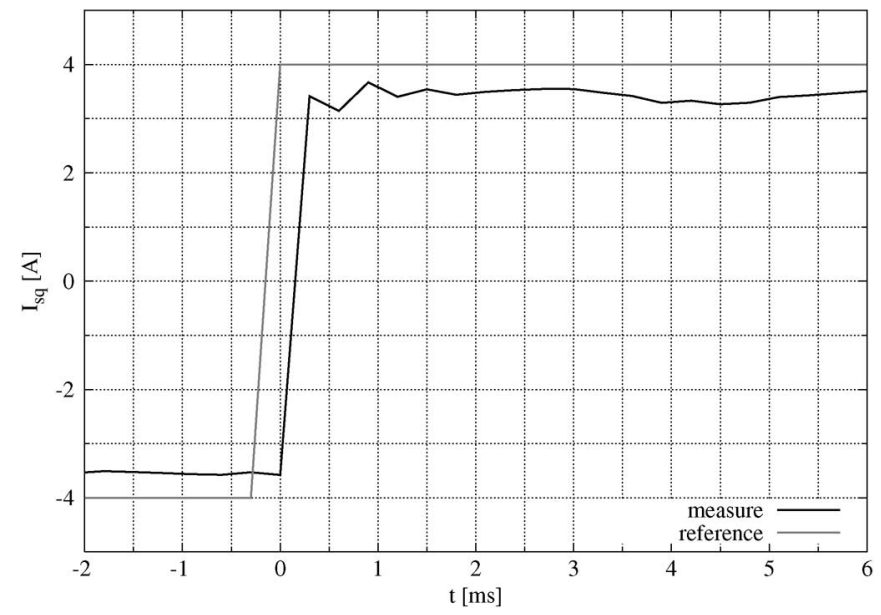

Fig. 21. MSHC: $q$-axis current evolution during a transient from $I_{\mathrm{sq}}^{\#}=-4 \mathrm{~A}$ to $I_{\mathrm{sq}}^{\#}=+4 \mathrm{~A}$.

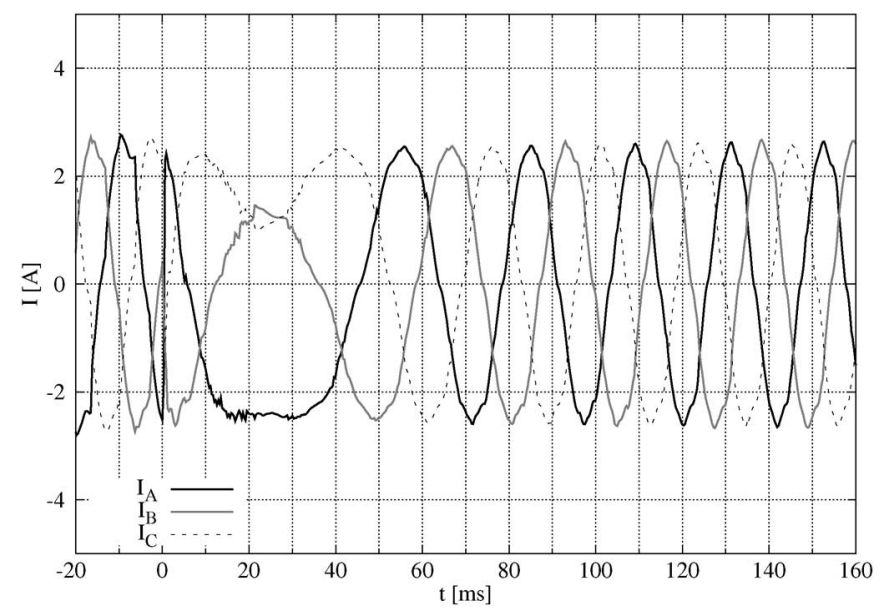

Fig. 22. MSHC: Evolution of the stator currents during a transient from $I_{\mathrm{sq}}^{\#}=-4$ A to $I_{\mathrm{sq}}^{\#}=+4 \mathrm{~A}$.

greater than for vector control (1 A). This is due to the minimum application time as previously underlined.

\section{Multistep Hybrid Control (MSHC)}

MSHC was implemented on the same controller board as vector control. The minimum application time was fixed at $5 \mu \mathrm{s}$ as the dead-time of the inverter was set at $3 \mu \mathrm{s}$. The algorithm of MSHC was implemented in $\mathrm{C}$ language. The effective duration of computation is slightly less than $300 \mu$ s, which is shorter than the duration obtained with the vector control thanks to the implementation made directly in $\mathrm{C}$ language. This produces a better optimized code than the automatically generated code by Simulink. The sampling time has been fixed at $300 \mu$ s. The modulation period must be short enough to obtain a small current ripple during steady-state operation. It has been set to the same value as for the vector control, i.e. $100 \mu$ s. Consequently, the switching state sequence (Fig. 11) determined every $300 \mu \mathrm{s}$ is applied for three modulation periods. Thanks to specific outputs usually included in computing units, the implementation of this kind of sequence comes without difficulty. 
TABLE III

COMPARISON OF EXPERIMENTAL RESULTS

\begin{tabular}{c||c|c|c|c|c|c}
\cline { 2 - 7 } & Computation Occurrence & Modulation Period & Rise Time & q-axis Overshoot & q-axis Oscillation & q-axis Static Error \\
\hline \hline Vector Control & $1 \mathrm{~ms}$ & $100 \mu \mathrm{s}$ & $180 \mathrm{~ms}$ & $1 \mathrm{~A}$ & $0.3 \mathrm{~A}$ & negligible \\
\hline OSHC & between 10 and $100 \mu \mathrm{s}$ & none & $500 \mu \mathrm{s}$ & negligible & $1 \mathrm{~A}$ & $0.5 \mathrm{~A}$ \\
\hline MSHC & $300 \mu \mathrm{s}$ & $100 \mu \mathrm{s}$ & $500 \mu \mathrm{s}$ & negligible & $0.25 \mathrm{~A}$ & $0.5 \mathrm{~A}$ \\
\hline
\end{tabular}

Figs. 20-22 picture experimental results obtained with MSHC for $d$ - and $q$-axis phase currents. It can be seen that the $q$-axis current presents a very small oscillation $(0.25 \mathrm{~A})$ thanks to the switching state choice strategy adopted during the steady-state operation (Section IV-B). It can be noted that the steady-state operation is reached without any overshoot either for $I_{d}$ or for $I_{q}$. As it has been verified in simulation, the little error during steady-state operation $(0.5 \mathrm{~A})$ is due to voltage drops and dead-times in the inverter. On the one hand, due to voltage drops, phase voltages are smaller than expected, so phase currents are smaller than expected too. On the other hand, during a dead-time, phase currents flow through freewheeling diodes, so the direction of phase current flows determines phase voltages. For a positive (respectively, negative) phase current, a phase is connected to the negative (respectively, positive) dc voltage. As a result, during a dead-time, the current magnitude decreases whatever the current polarity [26], [27]. These two imperfections are not taken into account in the model so the actual state vector evolution is not the expected one but slightly smaller.

As $I_{\mathrm{sq}}$ is proportional to the electromagnetic torque [3], it can be noted that with MSHC, the electromagnetic torque inversion is obtained in less than $500 \mu$ s like with OSHC (to be compared with the $180 \mathrm{~ms}$ obtained with vector control) (Fig. 21).

The transient evolution of the three stator currents is shown in Fig. 22. It can be verified that there is no overcurrent during torque inversion and rotation direction inversion. This is an interesting feature for practical implementation: a current regulator is not necessary. Compared to vector control (Fig. 16), current magnitudes during steady-state operation are smaller due to the static error already mentioned.

Similar results have been obtained in many other different transient operations, in particular, with a transient from $I_{\mathrm{sq}}^{\#}=$ -6.3 A to $I_{\mathrm{sq}}^{\#}=+6.3 \mathrm{~A}$, which is equivalent to a nominal electromagnetic torque inversion for this machine.

The main comparative experimental results of a transient form $I_{\mathrm{sq}}^{\#}=-4$ A to $I_{\mathrm{sq}}^{\#}=+4$ A for vector control, OSHC and MSHC are summarized in Table III. Both OSHC and MSHC provide superior dynamic performance compared to vector control. For most practical applications, the hybrid control will be used inside a speed control loop, thus static errors are not an important limitation so far.

\section{CONCLUSION}

Two hybrid control strategies have been presented. These strategies are a general approach applicable for many PSS consisting of a continuous process having discrete control states. Both methods use a hybrid model in which both discrete and continuous processes are considered.
In the context of electrical motor drive, two hybrid control methods have been presented to realize the torque control by directly selecting the switching states of the inverter. The superior transient performance over classical vector control is demonstrated. Torque control is possible without any current regulator and no observer or estimator is necessary.

The first method, OSHC, having important real-time computation constraints, requires high performance hardware. The second one, MSHC, taking advantage of fixed modulation frequency, can be performed with cheaper controllers and leads to smaller current ripples.

Further work will be carried out on MSHC by taking into account defaults of inverters (like dead-times and switch voltage drops) to improve the static performances.

\section{REFERENCES}

[1] A. J. Van der Schaft and H. Schumacher, An Introduction to Hybrid Dynamical Systems. London, U.K.: Springer-Verlag, 2000.

[2] J. Buisson, H. Cormerais, M. Zainea, H. Gueguen, and E. Godoy, "Formal approach to compute hybrid automata models for linear physical systems with switches," in Proc. IEEE Int. Symp. Comput.-Aided Control Syst. Des., Cesson Sevigne, France, Sep. 2004, pp. 47-52.

[3] P. Pillay, "Vector control of AC permanent magnet machines," in Proc. 4th Int. Conf. Electr. Mach. Drives, London, U.K., Sep. 1989, pp. 293-297.

[4] W. Leonhard, Control of Electrical Drives, 2nd ed. Berlin, Germany: Springer-Verlag, 1990. $346 \mathrm{pp}$.

[5] I. Takahashi and T. Noguchi, "A new quick-response and highefficiency control strategy of an induction motor," IEEE Trans. Ind. Appl., vol. IA-22, no. 5, pp. 820-827, Sep./Oct. 1986.

[6] P. Vas, Sensorless Vector and Direct Torque Control. London, U.K.: Oxford Univ. Press, 1998. 560 p.

[7] G. S. Buja and M. P. Kazmierkowski, "Direct torque control of PWM inverter-fed AC motors-A survey," IEEE Trans. Ind. Electron., vol. 51, no. 4, pp. 744-757, Aug. 2004.

[8] A. Linder and R. Kennel, "Model predictive control for electrical drives," in Proc. 36th IEEE PESC, Recife, Brazil, Jun. 2005, pp. 1793-1799.

[9] A. Linder and R. Kennel, "Direct model predictive control-A new direct predictive control strategy for electrical drives," in Proc. 11th Conf. EPE, Dresden, Germany, Sep. 2005. [CD-ROM].

[10] J. Rodriguez, J. Pontt, C. Silva, P. Cortez, U. Amman, and S. Rees, "Predictive current control of a voltage source inverter," in Proc. 35th IEEE PESC, Aachen, Germany, Jun. 2004, pp. 2192-2196.

[11] J. Rodriguez, J. Pontt, C. Silva, M. Salgado, S. Rees, U. Ammann, P. Lezana, R. Huerta, and P. Cortes, "Predictive control of three-phase inverter,” Electron. Lett., vol. 40, no. 9, pp. 561-563, Apr. 2004.

[12] J. Rodriguez, J. Pontt, C. A. Silva, P. Correa, P. Lezana, P. Cortes, and U. Ammann, "Predictive current control of a voltage source inverter," IEEE Trans. Ind. Electron., vol. 54, no. 1, pp. 495-503, Feb. 2007.

[13] J. M. Retif, X. Lin-Shi, A. Llor, and F. Morand, "New hybrid direct-torque control for a winding rotor synchronous machine," in Proc. 35th IEEE PESC, Aachen, Germany, Jun. 2004, pp. 1438-1442.

[14] X. Legrand, J. M. Retif, M. Smaoui, X. Brun, D. Thomasset, and X. F. Lin-Shi, "Hybrid control with on/off electropnaumatic standard valve for tracking positioning," in Proc. Bath Workshop Power Transmiss. Motion Control, Bath, U.K., Sep. 2005, pp. 45-58.

[15] A. Sellier, X. Brun, S. Sesmat, J. M. Retif, X. F. Lin-Shi, D. Thomasset, and M. Smaoui, "Hybrid force control with on/off electro-pneumatic standard distributors," J. Fluid Power, vol. 7, no. 1, pp. 51-59, Mar. 2006.

[16] M. S. Branicky, V. S. Borkar, and S. K. Mitter, "A unified framework for hybrid control: Model and optimal control theory," IEEE Trans. Autom. Control, vol. 43, no. 1, pp. 31-45, Jan. 1998. 
[17] H.-T. Moon, H.-S. Kim, and M.-J. Youn, "A discrete-time predictive current control for PMSM," IEEE Trans. Power Electron., vol. 18, no. 1, pt. 2, pp. 464-472, Jan. 2003.

[18] M. Nemec, D. Nedeljkovic, and V. Ambrozic, "Predictive torque control of induction machines using immediate flux control," IEEE Trans. Ind. Electron., vol. 54, no. 4, pp. 2009-2017, Aug. 2007.

[19] R. Morales-Caporal and M. Pacas, "A predictive torque control for the synchronous reluctance machine taking into account the magnetic cross saturation," IEEE Trans. Ind. Electron., vol. 54, no. 2, pp. 1161-1167, Apr. 2007.

[20] V. Ambrozic, G. S. Buja, and R. Menis, "Band-constrained technique for direct torque control of induction motor," IEEE Trans. Ind. Electron., vol. 51, no. 4, pp. 776-784, Aug. 2004.

[21] M. Pacas and J. Weber, "Predictive direct torque control for the PM synchronous machine," IEEE Trans. Ind. Electron., vol. 52, no. 5, pp. 13501356, Oct. 2005

[22] V. Ambrozic, R. Fiser, and D. Nedeljkovic, "Direct current control-A new current regulation principle," IEEE Trans. Power Electron., vol. 18, no. 1, pp. 495-503, Jan. 2003.

[23] M. Pacas and J. Weber, "Predictive direct torque control for the PMsynchronous machine," in Proc. 29th Annu. Conf. IEEE IECON, Roanoke, VA, Nov. 2003, vol. 2, pp. 1249-1254.

[24] H. Abu-Rub, J. Guzinski, Z. Krzeminski, and H. A. Toliyat, "Predictive current control of voltage-source inverters," IEEE Trans. Ind. Electron., vol. 51, no. 3, pp. 585-593, Jun. 2004.

[25] P. Correa, M. Pacas, and J. Rodriguez, "Predictive torque control for inverter-fed induction machines," IEEE Trans. Ind. Electron., vol. 54, no. 2, pp. 1073-1079, Apr. 2007.

[26] L. Ben-Brahim, "The analysis and compensation of dead-time effects in three phase PWM inverters," in Proc. 24th Annu. Conf. IEEE IECON, Aachen, Germany, Sep. 1998, vol. 4, pp. 792-797.

[27] L. Ben-Brahim, "On the compensation of dead time and zero-current crossing for a PWM-inverter-controlled AC servo drive," IEEE Trans. Ind. Electron., vol. 51, no. 5, pp. 1113-1118, Oct. 2004.

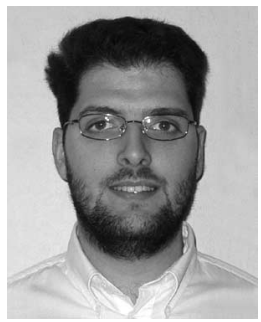

Florent Morel (S'06-M'07) received the Agrégation in electrical engineering from the École Normale Supérieure de Cachan, Cachan, France, in 2002 and the M.S. and Ph.D. degrees in electrical engineering from the Institut National de Sciences Appliquées, Lyon, France, in 2004 and 2007, respectively.

$\mathrm{He}$ is currently with AMPERE, Lyon. His research concerns control applied to power electronics systems.

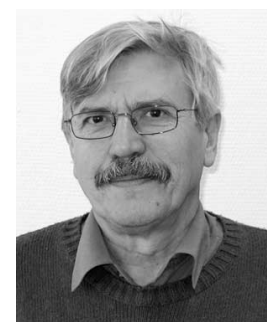

Jean-Marie Rétif received the Ph.D. degree in tuning control from Claude Bernard University, Lyon, France, in 1979

$\mathrm{He}$ has been with the Laboratory of Energetic and Control of INSA Lyon, where he deals with different subjects such as process control and optimization of solar heating. Since 1979, he has been working on the control of electrical engineering systems at the CEGELY. He is interested in the control of hybrid dynamic systems and applications concerning power systems.

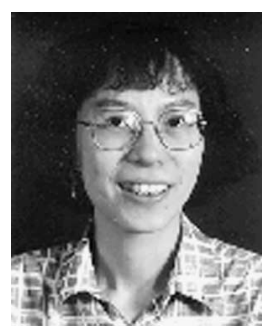

Xuefang Lin-Shi received the Ph.D. degree in applied computer science and automatic from Institut National des Sciences Appliquées de Lyon (INSA Lyon), Villeurbanne, France, in 1992.

Since 1994, she has been an Associate Professor at the Electrical Engineering Department, INSA Lyon and has joined the Electrical Engineering Center of Lyon. Her research interests concern control applied to electrical drives and, recently, to hybrid dynamic systems.

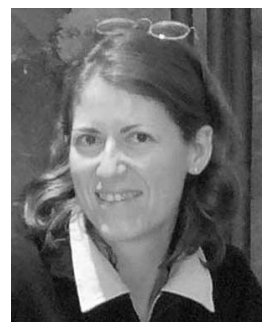

Claire Valentin received the B.S. degree in electrical and automatic control engineering from the Institut National Polytechnique de Grenoble, and the $\mathrm{Ph} . \mathrm{D}$. degree from Laboratoire d'Automatique de Grenoble, France, in 1989 and 1993, respectively.

She was qualified to direct research activities in 2005 and is currently a Research Associate Professor at the University of Lyon in the Automatic Control and Process Engineering Department, France. Her research interests include the Hybrid Dynamic Systems modeling, analysis and control with energy based theory such as Hamiltonian formulation and Dirac structures, or mixed Petri nets, and their applications to electrical power converters, multibatchmultiproducts systems and chemical nonlinear processes. 